\title{
LA IDENTIDAD DE GÉNERO COMO UN DERECHO DE LIBERTAD*
}

\author{
Valentina Verbal Stockmeyer \\ Horizontal
}

Resumen: Teniendo a la vista el intenso debate que generó el proyecto de ley de identidad de género en Chile, la autora cuestiona la visión esencialista de la sexualidad humana de algunos actores y realiza una defensa del derecho a la identidad de género desde algunos principios fundamentales del liberalismo clásico, entendiéndolo, por tanto, como una parte de la libertad de acción individual que, en el marco de una sociedad libre, debería ser respetada y garantizada.

Palabras Clave: identidad de género, libertad individual, liberalismo clásico, Hayek.

Valentina Verbal. Historiadora. Licenciada por la Universidad de los Andes y magíster por la Universidad de Chile. Profesora en la Universidad Autónoma de Chile. Directora de formación del centro de estudios Horizontal. Email: valeverbal@, gmail.com.

* Versión extendida de la conferencia pronunciada en el Centro de Estudios Públicos el 28 de marzo de 2018, en el panel "Feminismo, diversidad e identidad". La autora agradece los generosos comentarios de Felipe Schwember y Benjamín Ugalde, pero aclara que se hace enteramente responsable de los errores u omisiones que este trabajo pueda contener. 


\section{GENDER IDENTITY AS A RIGHTFUL FREEDOM}

ABSTRACT: Considering the intense debate over the gender identity bill in Chile, the author questions the essentialist view of human sexuality and mounts a defence of the right to gender identity on the basis of certain fundamental principles of classical liberalism, thus treating it as an aspect of individual freedom of action that ought to be respected and upheld in a free society.

KEYwords: gender identity, individual freedom, classical liberalism, Hayek.

\section{INTRODUCCIÓN}

D

urante los últimos meses del segundo gobierno de Michelle Bachelet (2014-2018), así como en los primeros del también segundo mandato de Sebastián Piñera (2018-2022), Chile se vio enfrentado a una intensa polémica a partir de la discusión del proyecto de ley que "reconoce y da protección al derecho a la identidad de género". 1

Cuando parecía que ya se habían calmado las aguas en torno a las llamadas "cuestiones valóricas"2 — luego de aprobarse el proyecto de ley de aborto en tres causales ${ }^{3}$ y antes, en 2015, el Acuerdo de Unión Civil_ , ${ }^{4}$ la mencionada iniciativa "se tomó" la agenda de los medios de

${ }^{1}$ Boletín 8924-07. Este proyecto de ley fue ingresado el 7 de mayo de 2013 por los senadores Camilo Escalona, Ricardo Lagos Weber, Juan Pablo Letelier, Lily Pérez y Ximena Rincón, quedando inicialmente radicado en la Comisión de Derechos Humanos, Nacionalidad y Ciudadanía. En adelante, esta iniciativa será frecuentemente referida como "el proyecto". Al cierre de este número de Estudios Públicos, la ley había sido aprobada por el Congreso y se hallaba en trámite frente al Tribunal Constitucional, en lo que al control preventivo de constitucionalidad se refiere, dado que modifica normas orgánicas constitucionales. Sin embargo, y en vista de que aquí no se entrará en sus detalles específicos, las consideraciones de fondo de este trabajo se mantienen inalterables.

${ }^{2}$ Normalmente asociadas, en Chile, a la autonomía personal con relación a la sexualidad, a la familia y, en algunos casos, a la vida (aborto y eutanasia, como ejemplos del último caso).

${ }^{3}$ Ley que regula la despenalización de la interrupción voluntaria del embarazo en tres causales, n. $^{\circ} 21030$, promulgada el 14 de septiembre de 2017 y publicada el 23 de septiembre del mismo año.

${ }^{4}$ Ley que crea el Acuerdo de Unión Civil, n. ${ }^{\circ} 20.830$, promulgada el 13 de abril de 2015 y publicada el 21 de abril del mismo año. 
comunicación, tanto las últimas semanas de Bachelet, como los primeros meses de Piñera.

Un ejemplo, entre otros, de esta polémica es el siguiente. Durante un foro, organizado por la Asociación de Radiodifusores de Chile (Archi, 7 de diciembre de 2017), el todavía candidato Piñera señaló no estar de acuerdo con el hecho de que los menores de edad puedan modificar su sexo registral "casi sin ningún trámite", ya que el "género no puede ser como una camisa que uno se cambia todos los días", agregando que "muchos casos de disforia de género se corrigen con la edad" (El Mostrador 2017). ${ }^{5}$ Más tarde, ya durante el primer mes de su nuevo gobierno - y, al parecer, influido por el Oscar obtenido por la película Una mujer fantástica-, Piñera optó por introducir indicaciones y apoyar el cambio de sexo registral, al menos para adolescentes (entre $14 \mathrm{y}$ 17 años), bajo la representación de sus padres y por intermedio de un Tribunal de Familia, lo que le generó fuertes roces con el ala más conservadora de la Unión Demócrata Independiente (UDI), liderada por la senadora Jacqueline van Rysselberghe. ${ }^{6}$

Por otra parte, el proyecto provocó una fuerte reacción de sectores conservadores del mundo de la sociedad civil, los que, al igual que en casos anteriores, han visto en dicha iniciativa una suerte de destrucción del "orden moral" en materia de sexualidad humana y que, por supuestas razones de bien común, el Estado debería preservar y fomentar.

Se trata de una visión esencialista, según la cual del sexo biológico de las personas se derivarían, de manera directa y como una suerte de "destino manifiesto", sus orientaciones sexuales, identidades de género y roles de género. ${ }^{7}$ Esto significa que, asumiendo para sí una determina-

${ }^{5}$ Todas las referencias a notas de prensa, entrevistas y columnas de opinión pueden fácilmente encontrarse en internet a través de sus mismos títulos, por lo que no se incluirán en este artículo los enlaces respectivos.

${ }^{6}$ Finalmente, en el caso de los menores de edad, el Congreso sólo autorizó el cambio de sexo registral para los mayores de 14 años y menores de 18 años, bajo la jurisdicción de los tribunales de Familia y con el acompañamiento de sus padres. Para los mayores de edad, el trámite se podrá realizar de manera administrativa, ante el Registro Civil.

${ }^{7}$ La orientación sexual "se refiere a la capacidad de cada persona de sentir una profunda atracción emocional, afectiva y sexual por personas de un género diferente al suyo, de su mismo género o de más de un género, así como a la capacidad de mantener relaciones íntimas y sexuales con estas personas". Principios de Yogyakarta (2006), 6. El rol de género, según la Organización Panamericana de 
da concepción de la vida buena, el Estado debería privilegiar las orientaciones heterosexuales, las identidades cisgénero (no trans) ${ }^{8} \mathrm{y}$, finalmente, los roles de género asociados a lo que culturalmente se entiende como masculino y femenino.

Este trabajo, que tiene como telón de fondo el debate que la iniciativa de ley referida generó en Chile, apunta a problematizar la visión patologizante de las identidades trans, ofreciendo una defensa del derecho a la identidad de género desde algunos principios fundamentales del liberalismo clásico, el que, desde ya y en términos generales, puede ser entendido como la garantía constitucional de los derechos del individuo frente al poder del Estado. ${ }^{9}$

Dado que sobre los principios liberales se profundizará más adelante, ${ }^{10}$ definamos aquí dos conceptos claves para los efectos de este trabajo: identidad de género y trans. El primero se refiere a la "percepción de una persona de ser hombre, mujer, o alguna alternativa de género o combinación de géneros". ${ }^{11}$ Trans, por su parte, es un adjetivo utilizado "como un término general para referirse a personas cuya identidad y/o expresión de género no se corresponde con las normas y expectativas sociales tradicionalmente asociadas con su género al nacer". ${ }^{12}$

la Salud (OPS), puede entenderse como sigue: "Conjunto de normas sociales y de comportamiento, y las expectativas relacionadas con las diferentes categorías de identidades sexuales y de género en una determinada cultura y periodo histórico". OPS, Por la salud de las personas trans (2013), 20. El término identidad de género, así como el de trans, se definirá más abajo en el cuerpo de esta misma introducción.

${ }^{8}$ El término cisgénero se aplica a aquellas personas cuya identidad de género es concordante con su sexo de nacimiento. El prefijo cis significa, según al Diccionario de la Lengua Española (DLE), "de la parte o del lado de acá". Por ejemplo, cisandino significa "más acá de los Andes". En este sentido, en términos literales, cisgénero quiere decir "más acá del género", contraponiéndose a transgénero que implica ir más allá del género.

${ }^{9}$ Partiendo de la base de que existe una pluralidad de liberalismos, Nicola Matteucci sostiene que "el único común denominador entre posiciones diversas es la defensa del Estado liberal, que nació antes del uso político del término liberal: un Estado que termina por garantizar los derechos del individuo frente al poder político". "Liberalismo", en Diccionario de política [1976], dirigido por Norberto Bobbio, Nicola Matteucci y Gianfranco Pasquino (Madrid: Alianza Editorial, 1991), 879 .

${ }^{10}$ Especialmente, en la cuarta sección de este trabajo.

11 OPS, Por la salud, 20.

12 OPS, Por la salud, 22. 
En lo que sigue, se procederá del siguiente modo. En primer lugar (2), se abordará la visión de Thomas Szasz sobre la psiquiatría institucional, en tanto entidad que, en conjunto con el Estado, apunta a la formación de un orden moral colectivo, por la vía de deshumanizar y segregar a las personas que no aceptan someterse a dicho orden. Luego (3), se cuestionará la patologización mental de las identidades trans, dando cuenta del tránsito de un paradigma de la enfermedad hacia uno de la diversidad, refiriendo algunas críticas al primero y explicando el significado del segundo, como desafío radical al binarismo de género. Posteriormente (4), se defenderá el derecho a la identidad de género desde algunos principios fundamentales del liberalismo clásico - individualismo, orden espontáneo y libertad individual—, especialmente a partir de la filosofía política de Friedrich Hayek. Por último (5), se concluirá subrayando la tesis central planteada en este trabajo.

\section{LA FABRICACIÓN DE LA LOCURA: LA VISIÓN DE THOMAS SZASZ}

En su libro La fabricación de la locura, publicado en 1970, el psiquiatra húngaro Thomas Szasz (1920-2012) efectúa una aguda comparación entre la Inquisición religiosa y la psiquiatría coercitiva, que denomina institucional. Demuestra Szasz, con gran erudición histórica, no sólo las similitudes entre ambas entidades, sino que también la continuidad temporal que ha existido entre ellas.

¿Cuáles son, para él, las similitudes entre la Inquisición y la psiquiatría institucional? En general, ambas se han sentido llamadas a defender un determinado orden moral, sobre el que se sustentaría la sociedad, en contra de los disidentes o inconformistas: personas que, aunque siendo minoritarias en términos estadísticos, afectarían la conservación de ese orden. Y ambas instituciones, además, se han constituido en "brazos armados del Estado" (esta expresión es mía) ${ }^{13}$ para identificar y sancionar a esas personas que, al mismo tiempo, se constituirían en víctimas propiciatorias necesarias.

${ }^{13}$ Aunque, a lo largo de su obra, Szasz plantea la misma idea, incluso de manera mucho más dura: “(...) la psiquiatría institucional (...) fue creada $-\mathrm{y}$ ha seguido siendo ininterrumpidamente - como una empresa colectivista, semi-totalitaria, en la que el médico servía al Estado y no al paciente". Thomas S. Szasz, La fabricación de la locura [1970] (Barcelona: Kairós, 2006), 221. 
Lo anterior es confirmado por una especialista en la historia de la (in)tolerancia en Occidente. Henry Kamen sostiene que ya, a "fines del siglo IV, la Iglesia había llegado a aceptar el uso de la coacción punitiva contra los cristianos heterodoxos y los católicos aprobaron las medidas que las autoridades seculares tomaron contra los arrianos y los donatistas". ${ }^{14}$ Esta situación se repetirá constantemente, mutatis mutan$d i$, en los siglos posteriores, incluso hasta en el presente.

La siguiente es la principal tesis que Szasz desarrolla en su libro: los colectivismos necesariamente apuntan a la construcción y conservación de un fin moral unitario, y para lograrlo, se orientan a fabricar, identificar y perseguir (de distintas maneras, según los diversos contextos históricos) a las personas que se apartan de ese fin definido como superior a los fines individuales.

Para el caso de la Inquisición, se trató de la defensa de un orden moral-teológico. Las víctimas propiciatorias fueron los herejes, los judíos y, muy especialmente, las brujas. Brujas y no brujos, es importante subrayar, pues éste es un ejemplo más de la constante histórica de subordinación de las mujeres a los hombres. En este contexto, en 1486 se publicó el famoso manual para cazadores de brujas, el Malleus Maleficarum, que estableció ciertas reglas para su adecuada identificación. Curiosamente, muy pronto "apareció una epidemia de brujería: creció el número de brujas, alentada encubiertamente su aparición por las mismas autoridades encargadas de su exterminio". ${ }^{15}$

La psiquiatría institucional, por su parte, se convirtió en la natural sucesora de la Inquisición a partir del siglo XVII, época en que los valores religiosos estaban dejando de ser preeminentes. De esta manera, la psiquiatría le vino como anillo al dedo a un ambiente cultural racionalista y laico. ¿Quiénes pasaron, ahora, a ser los disidentes?; ¿las víctimas propiciatorias que había que sacrificar? Los locos, posteriormente (sobre todo, en el siglo XX) calificados de "enfermos mentales". Y aquí es cuando entra en escena, no ya la muerte en la hoguera, sino el encierro en hospitales creados para el efecto. Como bien

${ }^{14}$ Henry Kamen, Nacimiento y desarrollo de la intolerancia en la Europa moderna [1967] (Madrid: Alianza Editorial, 1987), 15.

${ }^{15}$ Szasz, La fabricación, 20. 
lo ha documentado Michel Foucault, en el año 1656 se creó en París el Hospital General. ${ }^{16}$

Una gran pregunta es: ¿Cómo se definió la locura? O, dicho de manera más simple: ¿Quiénes son los locos? La definición fue excesivamente genérica: locos son los que es necesario encerrar, sean o no delincuentes. Aquí incluso estaban incluidos los pobres, los vagabundos, las madres solteras, sus hijos pequeños, las prostitutas, sus regentes, etcétera. ${ }^{17}$ Todos ellos debían ser separados del contacto con el resto. Lo importante era sacar de circulación a los peligrosos. Para lograr este objetivo, además, se hacía necesario estigmatizarlos y deshumanizarlos. ${ }^{18}$

Ahora bien, ¿cuál es el problema ético de todo lo anterior? Que, como dice Szasz: "Lo deprimente es que [tanto el inquisidor como el psiquiatra] ignoran que el supuesto doliente, sea de brujería, sea de enfermedad mental, quizás prefiera su soledad", ${ }^{19}$ en el sentido de que probablemente esa persona desee vivir su vida a su manera, sin ser juzgada y, menos todavía, encerrada por las autoridades eclesiásticas o psiquiátricas que actúan con la venia (coactiva) del Estado.

Porque, si bien es cierto que algunas personas atentan contra la libertad de otras en términos materiales (como el ladrón que ingresa en propiedad habitada a robar determinados bienes), éste no era el caso de las brujas o los locos. Por eso, mientras en el primer caso existía un daño del individuo sobre la persona o la propiedad de otro, en el segundo, no. El delito o la falta, en el segundo caso, consistía más bien en atentar contra el orden social en razón de la propia identidad, por

${ }^{16}$ Dice Foucault: “A primera vista, se trata solamente de una reforma, o apenas de una reorganización administrativa. Diversos establecimientos ya existentes son agrupados bajo una administración única: entre ellos, la Salpêtrière, reconstruida en el reinado anterior para usarla como arsenal". Michel Foucault, Historia de la locura en la época clásica [1964] (México D.F.: Fondo de Cultura Económica, 2010), tomo I, 80.

${ }^{17}$ Szasz, La fabricación, 27 y 28.

${ }^{18}$ David Cooper (1931-1986), para expresar la misma idea, utiliza el verbo invalidar: "En nuestra sociedad hay muchas técnicas que permiten primero señalar a ciertas minorías y luego tratarlas mediante un conjunto de operaciones de gravedad creciente, que van desde la insinuación al menosprecio, la exclusión de los clubes, escuelas o tareas, y otras medidas similares, hasta la invalidación total como personas, el asesinato y el exterminio en masa". David Cooper, Psiquiatría y antipsiquiatría (Barcelona: Paidós, 1985), 9.

${ }^{19}$ Szasz, La fabricación, 31. El destacado es mío. 
ser quién se era. Esa identidad ponía gravemente en riesgo el orden social, que era necesario preservar y que, constantemente, estaba - así se creía - en peligro de disolverse.

Es importante volver a subrayar la idea de Szasz según la cual los colectivismos se construyen a partir de la identificación de una víctima propiciatoria: un culpable que alejaría a la comunidad de su "bien común" o fin moral unitario, al que todos los individuos deberían subordinarse. Además, "es más fácil para el grupo protegerse de la acusación de estar oprimiendo a alguno de sus miembros, que para el individuo protegerse de la acusación de estar agraviando a la comunidad" 20 . En otras palabras, bajo este paradigma, las minorías podrían (e incluso, deberían) ser sacrificadas por el bien del conjunto. Y de ahí que sea muy importante "definir al Otro como un extraño, o como una persona alienada", ya que únicamente de esta manera es posible expulsarla de la categoría de normalidad. ${ }^{21}$

Esto es lo que Szasz denomina canibalismo simbólico, ya que, a diferencia de los sacrificios humanos de carácter físico, aquí se está en presencia de "caníbales existenciales o espirituales" que, para darles sentido a sus vidas, necesitan deshumanizar o invalidar las de los otros, que son aquellos que se rebelan frente al orden moral que se busca preservar e imponer. ${ }^{22}$

Por lo mismo, y con el objetivo de legitimar la separación de los disidentes de la mayoría, se hacía necesario catalogarlos como enfermos y criminales, a un mismo tiempo. Esto forma parte de la necesidad referida de deshumanizar a estas personas. Mientras que en el caso de las brujas se las asociaba con el envenenamiento, en los locos se lo hacía con el contagio. Los locos podían contagiar al resto. De ahí el imperativo de segregarlos. ${ }^{23}$

Resulta sorprendente constatar que, para la época en la que él vivía, ya en la temprana fecha de 1970 — hace 48 años—- Szasz denunciaba que unas de las principales víctimas propiciatorias del siglo XX habían sido los homosexuales. El delito de sodomía debía sancionarse mediante la pena de privación de libertad para evitar el contagio y el

\footnotetext{
${ }^{20}$ Szasz, La fabricación, 292.

${ }^{21}$ Ibídem, 297.

22 Ibídem, 301.

${ }^{23}$ Ibídem, 31.
} 
mal ejemplo. Los homosexuales hacían peligrar el orden que había que mantener.

¿Cuál era ese orden? Uno en que, primero, a través de la Iglesia y, luego, mediante la psiquiatría institucional (coercitiva), se dictaba a la gente lo que es "normal" y lo que es "desviado" en materia sexual. Con matices y atenuaciones, este orden todavía persiste en la actualidad. Y, sobre todo, aún existen importantes sectores de la sociedad que quieren mantenerlo en la mayor medida que les resulte posible. Estos sectores aspiran, en concreto, a que el Estado siga considerando a las personas LGBTI $^{24}$ como enfermas, delincuentes y de segunda categoría (en términos de derechos fundamentales). ¿Por qué? Precisamente, porque ellas — con su sola existencia - niegan ese orden necesario de preservar; orden que afirma que la sexualidad humana poseería una "función natural" - la procreación - que cabría imponer, al menos indirectamente, desde la autoridad política. ${ }^{25}$

Por lo mismo, para la conservación de tal orden, se hacía necesario considerar a los homosexuales como enfermos mentales y sodomitas, a la vez. En el fondo, como enemigos sociales. Pero Szasz señala que "la opinión psiquiátrica sobre los homosexuales no es una afirmación científica, sino un prejuicio médico". ${ }^{26}$ Incluso llega a decir que los "calvos prematuros son enfermos en un sentido más estricto del término, del que jamás podrá aplicarse a los homosexuales". ${ }^{27}$

Para el caso de Chile, se podrían poner diversos ejemplos del afán constante del mundo conservador por la preservación, mediante coacción, de un orden moral en contra de los homosexuales. Uno muy emblemático es la negativa a despenalizar la sodomía en 1999. De hecho, el gran argumento que esgrimieron los parlamentarios que sos-

${ }^{24}$ Sigla que alude a lesbianas, gays, bisexuales, trans e intersex. Para una explicación sintética de estos conceptos (y de otros relacionados), ver Comisión Interamericana de Derechos Humanos (CIDH), Estudio sobre orientación sexual, identidad de género y expresión de género: Algunos términos y estándares relevantes (2012).

${ }^{25}$ Digo indirectamente, porque, pese a que nadie se le obligaría a procrear, el orden político sí debería reconocer sólo las identidades sexuales que tienden a perpetuar la especie - las heterosexuales - , de modo que, al negarles tal reconocimiento a las homosexuales (y otras), se las discrimina de manera coercitiva, desde el aparato estatal.

26 Szasz, La fabricación, 166.

27 Ibídem, 158. 
tuvieron esta postura fue que era necesario mantener la tipificación de ese delito con el objetivo de enviar una "señal" a la sociedad de cuáles deberían ser los principios morales sobre los cuales ella tendría que fundarse.

El diputado Iván Moreira, militante de la Unión Demócrata Independiente (UDI), llegó, en ese entonces, a señalar: “Aunque en la práctica la sodomía no lleva a la detención o condena, es muy importante señal del legislador mantener el delito, pues es una muestra de que a la ley y por ende a la sociedad no les es indiferente el tema". Por su parte, su colega René Manuel García, de Renovación Nacional (RN), afirmó sin ambages: "Cuando se quiere modernizar así, se vulneran los principios más tradicionales de la patria. ¿Acaso Chile tiene tradición o cultura de homosexuales?"28

En ambos casos, se parte de la base de que es necesario que el Estado imponga un fin unitario en materia de moral sexual, y que apunte a la segregación de los homosexuales (y, por extensión, de todas las personas LGBTI). De esta manera, dichos parlamentarios le estaban diciendo al país que el Estado debía moralizarse; es decir, asumir como propia una determinada concepción de la vida buena: en este caso, en materia sexual.

Y si bien en Occidente - para la American Asociation of Psiquiatry (APA) desde 1973 - ya no se considera a la homosexualidad como una enfermedad mental, ${ }^{29}$ todavía hoy importantes sectores conservadores que estiman que sí lo sería. Por ejemplo, Hernán Corral Talciani, profesor de derecho civil de la Universidad de los Andes, señala abiertamente que: a) las relaciones homosexuales rebajan la dignidad humana, por ser injustas o contrarias a la naturaleza humana, y b) constituyen una desviación de carácter psiquiátrico. Sostiene, de un modo categórico, que "los actos de sodomía no son una forma natural de usar el sexo,

${ }^{28}$ Citado por Víctor Hugo Robles, Bandera hueca. Historia del movimiento homosexual en Chile (Santiago: Arcis - Cuarto Propio, sin fecha), 78.

${ }^{29} \mathrm{Si}$ bien se mantuvo como trastorno la llamada homosexualidad egodistónica, que se refiere a aquellas personas que se sienten disconformes con su homosexualidad, sufriendo ansiedad y el deseo de cambiar. Para este tema, ver Rafael Jiménez Díaz, "La génesis de las parafilias sexuales y la homosexualidad egodistónica: el modelo de los mecanismos tensionales", en Avances en Psicología Latinoamericana 30, n. $^{\circ} 1$ (2012): 146-158. 
sino manifestaciones de un desorden, disfuncionalidad o anomalía en el ejercicio de la sexualidad". ${ }^{30}$

Según Szasz, la gran lección de todo lo anterior es que "el hombre debe escoger para siempre entre la libertad y aquellos valores rivales, como salud, seguridad o bienestar. Si escoge, debe estar preparado a pagar su precio". Si se opta por la libertad, es necesario, concluye, estar dispuesto a oponerse "a las mayorías ilustradas, siempre dispuestas a reformar a las minorías descarriadas". ${ }^{31}$

Lo anterior supone, en definitiva, vindicar un orden social basado en la libertad individual, en contraste con la idea de que las personas deban subordinar sus fines propios a un fin colectivo, supuestamente necesario para el "bien" del conjunto.

\section{LAS IDENTIDADES TRANS: PATOLOGIZACIÓN Y DESPATOLOGIZACIÓN}

Pese a una campaña de ya varios años, impulsada desde el campo de la sociedad civil, ${ }^{32}$ las identidades trans todavía forman parte de los manuales de enfermedades mentales, tanto de la APA (Diagnostical and

${ }^{30}$ Hernán Corral Talciani, "Matrimonio, parejas del mismo sexo y derecho de familia", en Matrimonio en conflicto. Visiones rivales sobre el matrimonio entre personas del mismo sexo, editado por Mauro Basaure y Manfred Svensson (Santiago: Cuarto Propio, 2015), 195.

${ }^{31}$ Szasz, La fabricación, 145.

32 Se trata de la campaña internacional Stop Trans Pathologization (STP), surgida en el año 2009 y que inicialmente apuntaba a la descatalogación de las identidades trans del manual de la APA, en su versión V, publicada en 2013. Como se verá más abajo en el cuerpo de esta sección, esta meta no se logró, puesto que, pese a algunas modificaciones rescatables, las identidades trans se mantuvieron bajo la denominación de disforia de género. Actualmente, esta campaña se orienta a lograr el mismo objetivo original, pero con relación al manual de la Organización Mundial de la Salud (OMS), cuya versión XII debería publicarse en 2018. Un problema, al que se hará referencia en la cuarta sección de este trabajo, guarda relación con la manera de justificar el acceso a la salud transespecífica; es decir, a procedimientos de transición corporal de género, especialmente cuando éstos son proveídos por el Estado. Desde ya, digamos que la solución desde el activismo trans ha sido entender el concepto de salud como bienestar y no meramente como ausencia de enfermedad. Esta idea procede de la OMS: "La salud es un estado de completo bienestar físico, mental y social, y no solamente la ausencia de afecciones o enfermedades". Ver el preámbulo de su constitución, suscrita en 1946. 
Statistical Manual Mental Disorders, en adelante DSM) como de la Organización Mundial de la Salud (OMS), el llamado CIE-10.33

Curiosamente, muy pocos años después de la descatalogación de la homosexualidad, se incluyó la categoría transexualismo en la III versión del manual de la APA, publicada en 1980. Más tarde, en su IV versión, de 1994, esta categoría recibió la denominación de trastorno de identidad de género y, finalmente —en la V, de 2013-, la de disforia de género.

Sin entrar aquí a comparar los cambios que dichas versiones han supuesto, resulta importante relevar que, tal como el mismo Szasz ha argumentado in extenso - en particular, al referirse a lo que describe como canibalismo simbólico-, el hecho de que algunas personas se encuentren catalogadas como enfermas mentales constituye una fuente de grave daño en contra de ellas, especialmente a partir de la imposición de un estigma muy difícil de borrar.

En este sentido, el psiquiatra húngaro es categórico cuando señala que "el vocabulario empleado en los diagnósticos psiquiátricos es, de hecho, una retórica de rechazo justificatoria y seudomédica", que apunta a hacer de "los psiquiatras fabricantes de estigmas médicos" y a los hospitales, "fábricas destinadas a la producción en masa de dicho producto". ${ }^{34}$

Con relación a las personas trans, cabe, sin embargo, constatar que desde un paradigma de la enfermedad se ha ido, en los últimos años, transitando hacia un paradigma de la diversidad. ${ }^{35}$ El primero puede resumirse en la idea de que las identidades trans serían "trastornos" o "anormalidades", ${ }^{36}$ basadas en un supuestamente grave desajuste entre el cuerpo y la mente; desajuste que debería corregirse o normalizarse.

33 Organización Mundial de la Salud (OMS), CIE-10. Manual de trastornos mentales y del comportamiento. Descripciones clínicas y pautas para el diagnóstico (Madrid: Meditor, 1992).

${ }^{34}$ Szasz, La fabricación, 242.

${ }^{35}$ Para una descripción somera de este tránsito, puede revisarse Valentina Verbal, "Personas trans en Chile. ¿Por qué es necesaria una ley de identidad de género?", en Material(es) de formación general I DD.HH. (Santiago: Universidad Viña del Mar, 2014), 27-35.

${ }^{36}$ Cabe constatar que, en general, la psiquiatría opera desde las categorías de normalidad y anormalidad, no asociándose ellas necesariamente a factores de orden biológico o, específicamente, neuronal, sino a desviaciones de un comportamiento moral, considerado como un "ideal", que forma parte de una sociedad culturalmente dada, y al que cabría someterse sin conflictos. Para este tema, ver Ricardo Capponi M., Psicopatología y semiología psiquiátrica [1987] (Santiago: Universitaria, 2016), "Introducción". 
Para dicha corrección o proceso de normalización, se suelen ofrecer dos caminos alternativos: a) corporal: en cuanto solución necesariamente biomédica, apunta a la adecuación del cuerpo a la mente, o b) mental: invocado por los conservadores, se orienta a rechazar de un modo categórico las reasignaciones (o transiciones corporales) de género. El camino biomédico da cuenta del lugar común, según el cual las personas trans nacerían en un "cuerpo equivocado". El mental sostiene que el "cambio de sexo" implicaría una imposibilidad de orden fáctico, especialmente desde un punto de vista genético, por lo que cualquier proceso rectificatorio de carácter civil debería ser rechazado de plano.

La solución biomédica se aprecia claramente en las dos últimas versiones del manual psiquiátrico de la APA. El DSM-IV sostiene que el trastorno de identidad de género se basa en una "identificación persistente con el otro sexo" (criterio diagnóstico A) y en el malestar, también persistente, con el sexo asignado al momento del nacimiento (criterio diagnóstico B). El criterio D, referido al "deterioro social y laboral" - y que alude a las graves discriminaciones sociales que sufren las personas trans-, si bien es mencionado, casi no es tomado en cuenta por el manual. ${ }^{37}$

El DSM-V, pese a algunos cambios acertados,${ }^{38}$ define la disforia de género como el "malestar que puede acompañar a la incongruencia entre el género experimentado o expresado por un sujeto y el género asignado". ${ }^{39}$ Aunque también incluye la idea de un deterioro social o laboral, igualmente da cuenta de una visión biologicista en torno a las identidades trans. Lo clave sería la incongruencia con el propio

${ }^{37}$ Asociación Americana de Psiquiatría (APA), DSM-IV-TR. Manual de diagnóstico y estadístico de los trastornos mentales (Barcelona: Masson, 2005), 645 y 646. Es importante aclarar que el criterio $\mathrm{C}$ se refiere al descarte de intersexualidad, que corresponde a "todas aquellas situaciones en las que el cuerpo sexuado de un individuo varía respecto al standar de masculinidad masculina o femenina culturalmente vigente". Mauro Cabral y Gabriel Benzur, "Cuando digo intersex. Un diálogo introducción a la intersexualidad", Cademus Pagu 24 (2005): 284.

${ }^{38}$ Por ejemplo, al distinguir entre las categorías de transexual y transgénero; al no reducir, así, las identidades trans a la cirugía de reconstrucción genital; y al reconocer la existencia de identidades de género alternativas al binario masculinofemenino.

${ }^{39}$ Asociación Americana de Psiquiatría (APA), DSM-5. Manual de diagnóstico y estadístico de los trastornos mentales (Madrid: Editorial Médica Panamericana, 2014), 451. 
cuerpo y el fuerte deseo de poseer los caracteres sexuales del "sexo opuesto". ${ }^{40}$

Pese a que ambas versiones del DSM no se pronuncian detalladamente sobre los procesos de reasignación de sexo, ${ }^{41}$ no es difícil inferir que la solución que proponen es de carácter biomédico. Por lo demás, la práctica indica la conexión frecuente entre la certificación psiquiátrica, en base a dicho manual, y las posteriores terapias hormonales y cirugías de reconstrucción genital.

Por su parte, el camino mental del paradigma de la enfermedad rechaza de plano las transiciones corporales, así como el reconocimiento legal de las identidades trans, puesto que - como ya se dijo - cambiar de sexo daría cuenta de una imposibilidad fáctica. En este sentido, Catalina Siles y Gustavo Delgado afirman que la teoría de género - entre cuyas manifestaciones incluyen a las identidades trans- expresaría una "“contrarrealidad artificial', que abandona todo lazo con lo naturalmente humano". Pero, además, dicha teoría constituiría una "concepción dualista de la personalidad humana"; es decir, una separación entre la conciencia y el cuerpo, que llevaría a que se perdiera todo "horizonte de significación, más allá de la pura búsqueda del placer". ${ }^{42}$

En sede académica, la visión precedente puede leerse en el jurista argentino Mauricio Luis Mizhari, quien sostiene que "en el transexual se ha producido, en esencia, una falla estructural, que le impide asumir la diferenciación sexual, y esa inaccesibilidad psíquica a la diferencia retorna con una falsa convicción de pertenecer al otro sexo". ${ }^{43}$

Sin embargo, las visiones precedentes no se corresponden con la realidad que viven las personas trans cuando transitan de género: no es que ellas quieran (o crean que pueden) "cambiar de sexo". Lo que ellas

${ }^{40}$ APA, DSM-5, 452 y 453.

41 Para los estándares médicos en materia de transición corporal de género, resulta fundamental considerar el manual de la World Professional Association Transgender Health (WPATH), Normas de atención para la salud de personas trans y con variabilidad de género (2012). Este documento — que en inglés se denomina Standars of Care (SOC) - se puede descargar, incluso en lengua castellana, en el sitio www.wpath.org.

42 Catalina Siles y Gustavo Delgado, "Teoría de género: ¿de qué estamos hablando? 5 claves para el debate", Documento de Trabajo del Instituto de Estudios de la Sociedad (IES) y Comunidad y Justicia (CJ) (Santiago: IES, 2014): 8 y 10.

${ }^{43}$ Mauricio Luis Mizhari, Homosexualidad y transexualismo (Buenos Aires: Astrea, 2016), 51. El destacado es del original. 
pretenden es más bien vivir socialmente una identidad de género que no está de acuerdo con las expectativas que, conforme a una visión binaria y biologicista de la sexualidad humana, deberían cumplir. Las transiciones de género de carácter corporal, en tanto, pueden asumir distintos grados, dependiendo de la voluntad libre de cada persona.

Son diversas las críticas - teóricas y prácticas - que es posible hacerle al paradigma de la enfermedad, independiente de los caminos en que pueda expresarse de manera concreta. En primer término, aunque no cabe duda de que el camino biomédico (al menos) resulta más empático con las personas trans - y que, a diferencia del mental, se orienta a reafirmar la identidad de género de quienes desean efectuarse cambios corporales - , lo cierto es que ambos, mirados ahora como un todo, terminan siendo ambiguos respecto del lugar en que sitúan el "problema" de las identidades trans, si en el cuerpo o en la mente. Por ello, Miguel Missé y Gerald Coll-Planas concluyen que "afirmar que el error tiene origen al mismo tiempo en el cuerpo y en la mente ${ }^{44}$ resulta contradictorio, pues si se trata de un fenómeno de origen biológico no debería clasificarse como un trastorno mental, y si tiene un origen puramente psíquico es difícilmente justificable una transformación física". 45

Asimismo, en segundo término, parece ser discutible que la raíz del malestar de las personas trans sea la disforia de género, entendida como la incomodidad profunda con el "sexo propio", puesto que centrar de manera principal el sufrimiento de ellas en la supuesta disforia que padecerían apunta a desconocer o minimizar el círculo vicioso (o cadena de discriminaciones sociales) de que son constantemente víctimas a partir de una primera discriminación estatal. ${ }^{46}$ En otras palabras, ello

${ }^{44}$ Lo que aplica para los dos caminos descritos, ya que ambos, aunque por distintas razones, están de acuerdo en la catalogación psiquiátrica de las identidades trans.

${ }^{45}$ Miguel Missé y Gerald Coll-Planas, "La patologización de la transexualidad. Reflexiones críticas y propuestas", Norte de Salud Mental VIII, n. 38 (2010): 48.

${ }^{46}$ Es lo que en otro lugar he denominado círculo trans, y que puede describirse del siguiente modo: para poder aspirar a un trabajo estable, se requiere que el documento nacional de identidad se corresponda con la identidad de género expresada; para modificar este documento, en lo que al nombre y sexo registral se refiere, un importante sector de los tribunales de justicia exige una cirugía genital; y para poder efectuarse esta cirugía, hay que disponer de dinero, que sólo es posible obtener a partir de un trabajo estable. Para un mayor desarrollo de este círculo, 
supone minimizar la invalidación coactiva que sufren; en particular, por el hecho de que el orden jurídico les niega el derecho a definir su propia identidad de género, precisamente por no corresponder al orden social que considera al sexo biológico como su causa directa.

En tercer término, desde una perspectiva clínica, resulta cuestionable la existencia de un "diagnóstico" de las identidades trans que, en definitiva, se reduce a si la persona se inclina hacia un patrón de estereotipos masculinos o femeninos. En esta línea de análisis, las psicólogas españolas María Fernández y Elena García-Vega señalan que las "escalas de masculinidad y feminidad no miden sentimiento de género", sino que más bien apuntan a medir el "grado de adecuación social [que] tiene una persona respecto a los estereotipos de masculinidad y feminidad". ${ }^{47}$

Lo anterior no quiere decir, por cierto, que no pueda - incluso en la infancia - determinarse si una persona es o no trans, pero no a partir del diagnóstico de una supuesta enfermedad, sino que de lo que la misma persona comunica de sí al resto. En otras palabras, del hecho de que ella exprese un profundo deseo de vivir de acuerdo a una identidad de género distinta de la que se le atribuye — por razones culturales - conforme a su sexo biológico.

puede verse Sebastián del Pino y Valentina Verbal, "El proyecto de ley de identidad de género. Una aproximación a sus disposiciones y fundamentos", Liminales. Escritos sobre psicología y sociedad 7, n. ${ }^{\circ} 1$ (2015), especialmente las páginas 194198. Afortunadamente, en los últimos años la jurisprudencia se ha ido orientando a conceder el cambio de nombre y sexo registral sin exigir como requisito previo la cirugía genital. Los abogados Nicolás Espejo y Fabiola Lathrop analizaron cuarenta causas con sentencia de término, en treinta y tres de las cuales se acogió la solicitud sin el requisito referido. Ver Nicolás Espejo Yaksic y Fabiola Lathrop Gómez, "Identidad de género, relaciones familiares y derechos de niños, niñas y adolescentes. Comentarios al proyecto de ley que reconoce y da proyección al derecho a la identidad de género", Revista de Derecho 22, n. ${ }^{\circ} 2$ (2015), 395 (nota al pie n. ${ }^{\circ} 4$ ). Pocos días antes del envío de este trabajo, causó gran impacto en los medios de comunicación de Chile una sentencia de la Corte Suprema que reconoció el derecho a la identidad de género de una mujer trans, sin la exigencia de una cirugía de reconstrucción genital previa. Para un contraste de visiones en torno a esta sentencia, pueden revisarse las columnas de los abogados Cristián Riego (a favor) y Álvaro Paul (en contra), "Frente a frente: ¿Es correcto el fallo de la CS que permite el cambio de nombre y sexo registral?", La Tercera, 9 de junio de 2018.

${ }^{47}$ María Fernández Rodríguez y Elena García-Vega, "Surgimiento, evolución y dificultades del diagnóstico de transexualismo", Revista de la Asociación Española de Neuropsiquiatría 32 (2012): 114. 
Por su parte, el paradigma de la diversidad puede desglosarse bajo tres premisas fundamentales. La primera es que las identidades trans no son enfermedades, sino manifestaciones (legítimas) de la diversidad humana; en este caso, de la diversidad sexual. La segunda es que dichas identidades forman parte de la construcción de un proyecto de vida propio, que no debería ser coartado, ni por terceros ni menos por el Estado. Y la última supone que no son —al menos, prima facie - consecuencia de modificaciones corporales. Estas últimas, siempre que surjan de decisiones personales y no producto de la coacción de agentes externos, pueden ciertamente ayudar a reafirmar la identidad de género ya existente - tanto en términos psicológicos como sociales-; sin embargo, sería un error ver en dichas modificaciones la causa de las identidades trans que se poseen. Por el contrario, son un efecto de éstas, toda vez que la identidad de género de las personas trans se encuentra presente desde la más temprana infancia. ${ }^{48}$

\section{LA IDENTIDAD DE GÉNERO: UNA DEFENSA LIBERAL CLÁSICA}

Desde una lectura somera del debate legislativo en torno al proyecto de identidad de género, puede constatarse una suerte de insuficiencia argumentativa en la postura a favor de éste. En ese sentido, la defensa del derecho a la identidad de género ha tendido a ser más bien emocional, voluntarista o basada en argumentos de autoridad.

Esta defensa puede apreciarse - de modo especial, aunque comprensivamente- en activistas trans. Por ejemplo, Andrés Rivera Duarte (quien nació con sexo biológico femenino) expone de manera directa la cruda realidad que enfrentan cotidianamente estas personas. Dice que, de la falta de reconocimiento del derecho a la identidad de género, se generan "una serie de violaciones conexas, como violación a los derechos del niño, el uso de la tortura, tratos inhumanos y degradantes, la detención arbitraria y la negación del empleo, de vivienda, de salud y de otros derechos protegidos por el derecho internacional". ${ }^{49}$

${ }^{48}$ Para una buena aproximación a este tema, ver Ximena de Toro, "Niños y niñas transgéneros: ¿nacidos en el cuerpo equivocado o en una sociedad equivocada?", Punto Género 5 (2015): 109-128.

49 Segundo Informe Complementario de la Comisión de Derechos Humanos, Nacionalidad y Ciudadanía, recaído en el proyecto de ley, en primer trámite constitucional, que reconoce y da proyección al derecho a la identidad de género (Valparaíso, 15 de diciembre de 2015), 32. 
Al decir que planteamientos como el anterior tienden a ser emocionales, voluntaristas o basados en argumentos de autoridad, no significa que sean errados o que no sea importante darlos a conocer. Lo que únicamente se quiere relevar es que apuntan a constatar una realidad dura, además de algunos estándares de derechos humanos que reconocen el derecho a la identidad de género. Y pese a que todo esto está muy bien, lo cierto es que dicha línea argumentativa no le hace mella a la postura conservadora, en buena medida porque no da cuenta — de manera directa, al menos - de la defensa de un orden social basado en la libertad individual versus un horizonte de sentido impuesto coactivamente desde el aparato estatal.

Una aproximación más cercana a una visión liberal puede, sin embargo, verse en algunos académicos que han argumentado a favor del derecho a la identidad personal, dentro del cual se encontraría el derecho a la identidad de género. En este sentido, Tomás Vial — profesor de derecho constitucional de la Universidad Diego Portales - sostiene que "este derecho implica, entre otros, el derecho a un nombre, el derecho a definir las relaciones familiares, el derecho a tener las características exteriores que individualizan a cada persona, su orientación sexual y su identidad de género". Y sostiene que se fundamenta en el principio de libertad personal, que "es un principio basal en nuestra carta fundamental" y que "implica el poder de decidir quién es uno". 50

Y aunque sea verdad, como afirman algunos juristas, ${ }^{51}$ que el derecho a la identidad personal sea - desde el punto de vista del sistema internacional de los derechos humanos - un derecho de tercera generación, lo cierto es que puede fundarse (y rastrearse) en algunos principios de filosofía política de ya varios siglos, y que recobraron su fuerza en el siglo XX frente al avance de algunos proyectos políticos de carácter totalitario o, al menos, de corte estatista. Uno de los pensadores liberales que, quizás con mayor ahínco, defendió estos principios en dicha centuria es Friedrich August von Hayek (1899-1992).

${ }^{50}$ Segundo Informe Complementario, 78.

${ }^{51}$ Ver, por ejemplo, Maricruz Gómez de la Torre, El sistema filiativo chileno (Santiago: Editorial Jurídica de Chile, 2007), 49. 
Pese a que muchas veces, y de manera caricaturesca, ${ }^{52}$ se lo reduce a un liberalismo meramente económico, lo cierto es que Hayek pensaba la libertad como un atributo moral de las personas. Esta consideración no resulta difícil de comprobar desde la lectura de Camino de servidumbre (1944), aunque aparezca mucho más nítida en Los fundamentos de la libertad (1960) y en Derecho, legislación y libertad, cuyo primer tomo fue publicado en $1973 .{ }^{53}$

Ya en la primera de estas obras, el pensador austriaco defiende la idea de que un orden social libre debería basarse en tres principios fundamentales: individualismo, orden espontáneo y libertad individual, siendo el tercero (al mismo tiempo) el fundamento y la consecuencia de los dos precedentes. ${ }^{54}$ Como veremos más adelante, el desarrollo de estos principios por parte de Hayek, si bien dan cuenta de un "sistema" original, se inscriben en una larga tradición del liberalismo clásico, especialmente de raíz británica.

¿Qué es el individualismo? Se trata de un principio de lento desarrollo en términos históricos, pero que — desde el Renacimiento y, sobre todo, desde las revoluciones liberales de los siglos XVII, XVIII

${ }^{52}$ Por ejemplo, el sociólogo mexicano Fernando Escalante Gonzalbo señala que, para Hayek, el "orden espontáneo es preferible, porque no necesita de la coerción, aunque genere algunos resultados indeseables. Lo malo es que para llegar a eso Hayek necesita ajustar la definición de tal manera que sólo pueda hablarse de coacción cuando una conducta es forzada a punta de pistola". Fernando Escalante Gonzalbo, Historia mínima del neoliberalismo. Una historia económica, cultural e intelectual de nuestro mundo, de 1975 hasta hoy (Madrid: El Colegio de México - Turner, 2016), 47. Esta cita no sólo da cuenta de una opinión discutible, sino derechamente errónea: Hayek no defiende la existencia de un orden espontáneo por no ser coercitivo, sino por apuntar a una diversidad de propósitos más que a uno centralizado. Luego, tampoco reduce la coacción a la fuerza física directa, sino que la amplía a la presión autoritaria que pueda afectar el ejercicio de la libertad. A este punto, me referiré en esta misma sección, al comparar la visión de Hayek con la de Rothbard.

${ }^{53}$ Este primer tomo es importante, porque aquí es donde Hayek desarrolla de manera más sistemática su teoría del orden espontáneo, de la que muy brevemente daré cuenta más abajo.

${ }^{54}$ Fundamento en cuanto la libertad, para Hayek, debería ser considerada como el gran principio ideológico que sostenga una sociedad abierta. Consecuencia en términos de que la libertad requiere de ciertas condiciones de posibilidad, de un contexto institucional, que apunte a la valoración de los individuos como tales y a la existencia de un conjunto de reglas del juego que permitan el despliegue — sin privilegios - de todos los proyectos de vida. 
y XIX - comenzó a significar "el respeto por el hombre individual qua hombre, es decir, el reconocimiento de sus propias opiniones y gustos como supremos en su propia esfera, por mucho que se estreche ésta, y la creencia en que es deseable que los hombres puedan desarrollar sus propias dotes e inclinaciones individuales". 55

Para Hayek, así como para tantos otros pensadores liberales, ${ }^{56}$ el gran enemigo del individualismo es el colectivismo. El individualismo, para él, "está dirigido primordialmente contra las teorías propiamente colectivistas de la sociedad, que pretenden ser directamente capaces de considerar a los conjuntos sociales, como la sociedad, y otras como entidades 'sui generis' que existen en forma independiente de los individuos que la componen". ${ }^{57}$

Dicho de una manera simple, el colectivismo (del signo que sea) ${ }^{58}$ apunta a considerar que los fines individuales - que pueden suponer proyectos particulares de vida en todos los planos, también en materia sexual- deberían subordinarse a un fin colectivo, que daría cuenta de un supuesto bien común, que puede llegar a considerar la existencia de formas de vida "superiores" versus otras "inferiores".

La gran conclusión de todo lo dicho es que "debe dejarse a cada individuo, dentro de los límites definidos, ${ }^{59}$ seguir sus propios valores y preferencias antes que los de otro cualquiera, que el sistema de fines del individuo debe ser supremo dentro de estas esferas y no estar sujeto al dictado de los demás". ${ }^{60}$ Es importante subrayar la insistencia del austriaco en torno a que el individuo es el "juez supremo de sus fines"

${ }^{55}$ Friedrich A. Hayek, Camino de servidumbre [1944] (Madrid: Alianza Editorial, 2007), 43.

${ }^{56}$ Por ejemplo, para Karl Popper el individualismo no se opone al altruismo (en el sentido de tender el egoísmo), sino al colectivismo (en cuanto éste establece un fin que limita los fines individuales). Dicho de un modo más ordenado, así como el individualismo es opuesto al colectivismo, el egoísmo lo es del altruismo. Ver Karl Popper, La sociedad abierta y sus enemigos [1945] (Barcelona: Paidós, 2017), 115.

${ }^{57}$ Friedrich A. Hayek, "El individualismo: el verdadero y el falso" [1945], Estudios Públicos 22 (1986): 6.

${ }^{58}$ No sólo el socialismo; también el fascismo, el comunitarismo, etcétera.

${ }^{59}$ Que se refiere al conocimiento parcial que los individuos tienen de las necesidades humanas, al punto de que las personas poseen sólo escalas parciales de valores, "que son inevitablemente diferentes y contradictorias entre sín". Hayek, Camino de servidumbre, 91.

${ }^{60}$ Ibídem. 
y que la noción según la cual las acciones de las personas deben estar gobernadas por sus fines propios (y no por los de otros) "constituye la esencia de la posición individualista". ${ }^{6}$

No creo que valga la pena explicitar demasiado que este primer principio les da la razón a quienes sostienen que las personas tienen derecho a buscar su propio destino, también en materia sexual, y que no tendrían por qué verse obligadas a subordinar esa búsqueda a un determinado fin unitario: a una precisa concepción de la vida buena que, por ejemplo, sostenga que las identidades trans constituyen "anormalidades" y que, por ello, las personas que las poseen deberían ser socialmente invalidadas, negándoles así el derecho a expresarlas y a fijarlas en sus documentos nacionales de identidad.

El segundo principio se refiere a la existencia de un orden espontáneo, que permita generar las condiciones de posibilidad para que "las acciones de los diferentes individuos y grupos" apunten a la consecución de "sus fines propios sobre la base de su propio conocimiento". ${ }^{62}$ Por eso es que Hayek cree en la libertad bajo la ley —en el rule of law - como el sometimiento de las acciones del Estado a "normas fijas y conocidas de antemano; normas que permiten a cada uno prever con suficiente certidumbre cómo usará la autoridad en cada circunstancia sus poderes coercitivos". ${ }^{63}$ Pero, a diferencia de un orden construido de manera autoritaria y deliberada, "las reglas que gobiernan un orden espontáneo deben ser independientes de cualquier objetivo, si no para todos, al menos para enteras clases de miembros no designados individualmente por su nombre". ${ }^{64}$

Esta célebre idea de Hayek resulta bastante cercana a la de razón pública de otro gran pensador liberal del siglo XX: John Rawls (19212002). Y dado que resulta imposible en tan corto espacio abordarla, consideremos sólo dos aspectos fundamentales. El primero es que no se basa en una doctrina moral, religiosa o política comprehensiva. Dice, a este respecto, Luis Villavicencio Miranda — profesor de la Facultad de Derecho de la Universidad de Valparaíso- : "En vez de mantener pri-

${ }^{61}$ Ibídem, 92.

${ }^{62}$ Friedrich A. Hayek, "Liberalismo", Revista de Ciencia Política 4, n. 2 (1982): 137.

${ }^{63}$ Hayek, Camino de servidumbre, 105.

${ }^{64}$ Friedrich A. Hayek, Derecho, legislación y libertad [1973] (Madrid: Unión Editorial, 2014), 72. Este volumen contiene los tres tomos de esta obra de Hayek. 
sioneros los principios políticos a una doctrina comprehensiva, el desafío [de la visión de Rawls] es construir una concepción que no dependa de la verdad de ningún sistema más o menos completo de carácter metafísico o epistemológico" ${ }^{65} \mathrm{Y}$ el segundo, consecuencia del anterior, es que constituye un mecanismo que garantiza el despliegue de las distintas concepciones morales. Dice, ahora, el mismo Rawls: "Suponemos que la diversidad de doctrinas razonables, religiosas, filosóficas y morales que se encuentra en las sociedades democráticas es una característica permanente de la cultura pública, y no una simple situación histórica que pronto desaparecerá". ${ }^{66}$

Como claramente explica Samuel Freeman —un estudioso del filósofo estadounidense-, la "idea de razón pública es fácilmente malentendida", puesto que no se refiere a "las razones que comparten en común las personas en una sociedad", ${ }^{67}$ sino a razones que satisfagan un "criterio de reciprocidad"; es decir, que se funden en premisas que otros razonablemente puedan aceptar. ${ }^{68}$ Dicho de una manera simple, así como el Estado debe garantizar la diversidad de concepciones de la vida buena, no debería imponer una sola al conjunto de la población. Esto no sería propio de una sociedad auténticamente libre.

De esta manera, ¿sería posible afirmar que el reconocimiento del derecho a la identidad de género apunta a beneficiar de manera particular a las personas trans? Sí, pero no - y esto es muy importante de puntualizar - para establecer derechos diferenciados con respecto a las personas cisgénero. Se trata de una normativa que busca, justamente, ponerlas a ellas en un pie de igualdad ante la ley; no a otorgarles beneficios legales o materiales a la manera de privilegios.

Por lo demás, cuando Hayek dice que las reglas sobre las cuales debería sustentarse un orden espontáneo han de ser generales, lo que quiere decir es que, además de ser igualitarias en el sentido ya indicado, "su aplicación debe ser independiente de cualquier fin común,

${ }^{65}$ Luis Villavicencio Miranda, Las críticas comunitaristas al liberalismo igualitario. Un balance (Alcalá de Henares: Universidad de Alcalá, 2014), 146. Samuel Freeman, Rawls (México D.F.: Fondo de Cultura Económica, 2016), 345.

66 John Rawls, El liberalismo político [1993] (México D.F.: Fondo de Cultura Económica, 2006), 207.

67 Samuel Freeman, Rawls (México D.F.: Fondo de Cultura Económica, 2016), 345 .

${ }^{68}$ Ibídem, 346. 
que los individuos no necesitan ni siquiera conocer", ${ }^{69}$ porque lo relevante es que - como ya se vio- hagan uso de su propio conocimiento para la consecución de sus propios fines, como si fueran fines supremos.

En este sentido, y a diferencia de un Estado colectivista, uno liberal no asume un único fin moral colectivo; por el contrario, busca que todos puedan perseguir sus propios fines o proyectos de vida, sin ser agredidos en el ejercicio de su libertad, ni por terceros ni menos todavía por el Estado, que es el ente - no hay que olvidarlo - que concentra el monopolio de la violencia física. ${ }^{70}$

Aclarado lo anterior, es importante subrayar que el reconocimiento del derecho a la identidad de género no apuntaba a imponer una visión esencialista de la sexualidad humana, sino precisamente a superar esta situación. Dicho de otra manera, lo que hace es trascender el canibalismo simbólico — volviendo a Thomas Szasz - de que han sido víctimas las personas trans, al ser consideradas como enfermas mentales y, por esta misma razón, negárseles el derecho a autodefinir su propia identidad de género.

Finalmente, el tercer principio que, no por más conocido tiende a ser mejor comprendido, es el de la libertad individual. Afirma Hayek que "el concepto de libertad de acción es mucho más amplio que el concepto de libertad económica, que a su vez incluye". ${ }^{71}$ Pero, teniendo ya claro que no defiende sólo un liberalismo económico, ¿qué es, para él, la libertad?: "El estado en que un hombre no se halla sujeto a coacción derivada de la voluntad arbitraria de otro o de otros". ${ }^{72}$

Al leer dicha definición de libertad, resulta fundamental revisar lo que Hayek entiende por coacción, dadas las repercusiones que un concepto demasiado estricto de la misma puede llegar a tener en el

${ }^{69}$ Ibídem.

70 Puede ser útil aquí recordar la clásica definición de Max Weber (18641920): "Estado es aquella comunidad humana que, dentro de un determinado territorio (...) reclama (...) para sí el monopolio de la violencia física legítima. Lo específico de nuestro tiempo es que a todas las demás asociaciones e individuos sólo se les concede el derecho a la violencia física en la medida en que el Estado lo permite. El Estado es la única fuente del 'derecho' a la violencia”. Max Weber, El politico y el cientifico (Madrid: Alianza Editorial, 1979), 83 y 84.

${ }^{71}$ Friedrich A. Hayek, Los fundamentos de la libertad [1959] (Madrid: Unión Editorial, 2014), 62.

${ }^{72}$ Ibídem, 32. 
discurso político. Esas repercusiones son patentes en algunos autores anarcocapitalistas que, en razón de la concepción estrecha de coacción que adoptan, pueden cerrarle la puerta a la diversidad. Por ejemplo, Murray Rothbard (1926-1995), un pensador canónico del anarcocapitalismo estadounidense, critica duramente la idea hayekiana según la cual la "coacción tiene lugar cuando las acciones de un hombre están encaminadas a servir la voluntad de otro; cuando las acciones del agente no tienden al cumplimiento de sus fines, sino al de los de otros". ${ }^{73}$

¿Cuál es, en concreto, la crítica que Rothbard le formula a Hayek? Que la noción de coacción del austriaco sería demasiado laxa. No se refiere sólo al "uso (o la amenaza de uso) invasor de la violencia física contra la persona o la (justa) propiedad de un tercero", ${ }^{74}$ dice el estadounidense, sino que podría extenderse a los casos de un "marido hosco' o de una esposa 'marimandona', capaces de hacer la vida insoportable a cualquiera, salvo que se someta voluntariamente a sus caprichos". 75

Específicamente, lo que Rothbard le imputa a Hayek es que vincula el concepto de coacción no sólo a violencia física, sino también a "ciertas formas de negativa pacífica y voluntaria a hacer intercambios". ${ }^{76}$ De hecho, sostiene Hayek que "la coacción implica que yo poseo la facultad de elegir, pero que mi mente se ha convertido en la herramienta de otra persona hasta el extremo de que las alternativas que se presentan a mi voluntad han sido manipuladas de tal suerte que la conducta que mi tirano quiere que elija se convierte para mí en la menos penosa" ${ }^{77}$ A diferencia de Rothbard, esta visión de Hayek —en la estela de otros importantes autores liberales - sí le abre la puerta a la diversidad como una característica esencial de un orden espontáneo o sociedad abierta.

¿Por qué la cuestión de la coacción, y la referencia a Rothbard, resulta fundamental para el tema que aquí nos ocupa? Porque, si bien, por ejemplo, es cierto que una persona trans puede, hoy en Chile, salir

${ }^{73}$ Ibídem, 177.

${ }^{74}$ Murray N. Rothbard, La ética de la libertad [1982] (Madrid: Unión Editorial, 2009), 289.

${ }^{75}$ Ibídem, 290.

${ }^{76}$ Ibídem.

${ }^{77}$ Hayek, Los fundamentos, 178. 
a la calle vestida de acuerdo a su identidad de género - $y$, en un sentido más amplio, efectuar una transición social de género-, el hecho de no contar, antes de la ley de identidad de género, con un documento nacional de identidad que le permita desenvolverse en la vida cotidiana de la misma forma en que lo puede hacer una persona cisgénero, puede perfectamente ser calificado como coacción. Y por eso es que una visión estrecha de la libertad — como la de Rothbard, que reduce la coacción a simple violencia física o amenaza de la misma- termina siendo inadecuada para pensar un orden social en que las personas tengan derecho a perseguir sus propios fines, más allá de la libertad meramente económica.

Para Hayek, en cambio, la sola restricción de las alternativas ${ }^{78}$ para elegir constituye coacción, ya que la libertad de la persona llega finalmente a someterse a la voluntad arbitraria de otro; en el caso del ejemplo, a la voluntad estatal, que se sustenta en una determinada concepción en materia de sexualidad y que termina coaccionando, en los términos referidos, a quienes la desafían.

En otras palabras, el hecho de que la libertad de esa persona trans se vea afectada por la voluntad del Estado, que le impide la búsqueda de su propio destino - representado, en el ejemplo, en la posesión de un documento nacional de identidad que refleje lo que ella es; no en términos biológicos, sino sociales-, da cuenta de la inexistencia, en su caso, de los principios de individualismo y orden espontáneo, que sí se aplicarían a las personas cisgénero. ¿Por qué?

En primer lugar, porque el Estado, desde una visión colectivista, reconoce como oficial una peculiarísima y muy controvertida concepción del sexo, el género, la identidad y, en definitiva, de la libertad sexual. Se trata de una visión esencialista, ya que considera que existiría una identidad sexual "natural", orientada fundamentalmente a la procreación.

$\mathrm{Y}$, en segundo lugar, porque dicho reconocimiento incumpliría el principio de igualdad ante la ley, que supone la ausencia de privilegios

${ }^{78}$ Es importante aclarar que, como se desprende del conjunto de su obra, por alternativas para la elección Hayek no entiende la posesión de determinadas condiciones materiales de vida ni menos todavía la garantía de algún resultado específico, a que puede dar lugar la acción de elegir. Simplemente, se refiere a la ausencia de coacción, entendida ésta como la voluntad arbitraria de otro que le impide, al agente, perseguir sus propios fines o proyectos de vida. 
en favor de ciertos grupos de personas y en contra de otros. En este caso, mientras los privilegiados son las personas cisgénero, los "otros" - que son discriminados estructuralmente - son todos quienes sienten y expresan una identidad de género distinta del sexo asignado al momento del nacimiento.

Pero, más allá de lo anterior, planteémonos esta pregunta: ¿Cómo se llega al hecho de que el Estado termine asumiendo como oficial una determinada concepción de la vida buena, concretamente en materia sexual? El planteamiento de Szasz, visto en la segunda sección de este trabajo, responde en buena medida a esta interrogante.

Por último, resulta muy discutible que la consideración del acceso a la salud transespecífica (enfocada a la transición corporal) como un "derecho", al que por tanto el Estado estuviese obligado, ayude a la validación del paradigma de la diversidad. ¿Es posible pensar que la invocación de un derecho - por definición universal y proveído por el Estado - constituya una adecuada herramienta — política y legal — en favor de ese paradigma y, por lo tanto, en contra del esencialismo conservador?

$\mathrm{Y}$ aunque resulte indiscutible que fundamentar - como, a nivel internacional, lo ha hecho el movimiento trans - ${ }^{79}$ el acceso a los tratamientos médicos en el concepto de salud, entendido como bienestar y no meramente como ausencia de enfermedad, constituye un avance importante, la idea de que exista un derecho a la salud y, a la inversa, un deber del Estado de proveerlo no logra cerrar el círculo en favor del derecho a la identidad de género desde el paradigma de la diversidad, sin que se vea sometido - sustantivamente - a un horizonte de sentido, moralizante y colectivista.

¿Significa lo anterior que el Estado no tiene nada que decir en materia de acceso a la salud transespecífica? No, no significa esto. Únicamente quiere decir que este acceso puede justificarse desde la libertad individual, incluyendo la ayuda estatal en favor de algunas

${ }^{79}$ Ver Jordi Mas Grau, Subjetividades y cuerpos gestionados. Un estudio sobre la patologización y medicalización del transgénero, tesis para optar al grado de doctor en antropología por la Universidad de Barcelona (2014); en particular, las páginas 217-219. 
personas trans, que se encuentren efectivamente en situación de vulnerabilidad. ${ }^{80}$

Dicho de otra forma, la concepción — propia del liberalismo clásico — de que el orden social legítimo, público y privado, descansa en la libertad individual debería llevar a reconocer el hecho obvio de que, en algunos casos, la voluntad de las personas no es perfecta; esto es, de que las personas, por las circunstancias en que actúan, no siempre pueden identificarse con el contenido de sus propias decisiones. Esta divergencia suele ser frecuente en materia laboral: muchas personas se ven en la necesidad de tener que aceptar trabajos de mala gana, ya que deben efectuar tareas que consideran indignas, pero que al menos les permiten poseer un empleo, con el que antes no contaban. Este es el caso, por lo demás, de las mismas personas trans, a quienes les cuesta mucho acceder a trabajos estables y no precarios. ${ }^{81}$

El filósofo chileno Felipe Schwember — profesor de la Universidad Adolfo Ibáñez, quien viene trabajando sobre la cuestión de la voluntariedad como eje de una teoría de justicia liberal - aclara que, en esos casos, las personas obran "en parte voluntaria y en parte involuntariamente y seguramente más del segundo modo que del primero". Se trata de lo que "Aristóteles llamaba actos mixtos de voluntario con involuntario". 82

Pero el hecho de que el Estado deba asumir un rol específico en ayuda de quienes se encuentran en situación de vulnerabilidad —en el sentido de no poder actuar con voluntad perfecta- no supone que las personas no sean libres y que, en consecuencia, deba su iniciativa ser

${ }^{80}$ Uso, en este trabajo, el término vulnerabilidad para referirme a las personas más desaventajadas. Olof Page distingue dos sentidos en torno a este concepto: "En un primer sentido, aquello que es vulnerable guarda relación con cuestiones materiales (económicas y/o acceso a bienes). En un segundo sentido, aquello a lo que se es vulnerable guarda relación con el no reconocimiento de aspectos de la propia identidad y/o con la pertenencia a determinado grupo (étnico o culturalmente definido)". Olof Page, "Las formas y usos de la vulnerabilidad", en Los invisibles. Por qué la pobreza y la exclusión dejaron de ser propiedad, editado por Catalina Siles V. (Santiago: Instituto de Estudios de la Sociedad, 2015), 34. En el caso de las personas trans, el segundo sentido explica en buena medida el primero.

${ }^{81}$ No necesito, me parece, justificar esta afirmación en algún estudio específico. Invito al lector cisgénero a que piense, por un momento, las dificultades a las que se enfrentaría a la hora de tener que buscar trabajo con un documento nacional de identidad que contenga una marca de género distinta de la expresada en la vida social.

${ }^{82}$ Felipe Schwember, "Igualdad o igualitarismo Dos perspectivas acerca de la justicia”, Estudios Públicos 147 (2017): 232. 
del todo reemplazada por el Estado. Sin embargo, la idea de los derechos sociales universales tiende a este reemplazo: a considerar que el "régimen de lo público"-y de una ciudadanía alineada con un horizonte de sentido de carácter colectivo_- ${ }^{83}$ sería contradictorio con un orden espontáneo en términos sociales. Este orden, empero, no desconfía de entrada en el mercado, sino que lo presupone como un sistema de cooperación pacífica y que, además, genera las condiciones de posibilidad en favor de la diversidad sexual, entre otras formas de diversidad. ${ }^{84}$

Por eso es que, en cambio, lo que habría que fortalecer es el poder de decisión de las personas, sin subordinar sus propios fines a un fin unitario de carácter moral. El mismo derecho a la identidad de género (y no sólo el acceso a la salud transespecífica) apunta a ese fortalecimiento. Pero lo importante es que la simetría que debería buscarse es que todos puedan identificarse con sus propias decisiones, que todos puedan decidir libre e individualmente, y no, como tienden a propugnar las visiones colectivistas de distintos sectores, aquella simetría que se impone a expensas de la posibilidad de las elecciones individuales y descentralizadas. En este sentido, y a la luz de todo lo dicho, parece no caber duda de que la identidad de género puede ser entendida y defendida como un derecho de libertad, desde algunos principios fundamentales del liberalismo clásico, como los vistos en este trabajo, a la luz del pensamiento de Hayek.

\section{CONCLUSIÓN}

A propósito del día de San Valentín, Lukas Berredo y Elías Jiménez se acercaron el 14 de febrero de 2013 a una de las oficinas del Registro Civil, en Santiago, a solicitar una hora para contraer matrimonio. El periódico The Clinic describía el hecho del siguiente modo: "Las

${ }^{83}$ Ver, por ejemplo, y pensando en el ciclo político iniciado en Chile en 2011, Fernando Atria et al., El otro modelo. Del orden neoliberal al régimen de lo público (Santiago: Debate, 2013).

${ }^{84}$ La célebre historiadora trans Deirdre McCloskey, en su visita a Chile en octubre de 2016, señaló que no es casualidad que el movimiento LGBTI —que, en un comienzo, se denominó del orgullo gay — haya nacido en un bar estadounidense, en Stonewall. Y, en efecto, no surgió de ninguna oficina estatal, sino, por el contrario, de agrupaciones sociales que querían resistir las redadas y hostigamientos policiales (estatales) que regularmente caían sobre dicho bar por acoger a lesbianas, homosexuales y trans. En otras palabras, los pioneros de este nuevo movimiento social surgieron en oposición a la coacción estatal y no en defensa de ella. 
fotografías del caso muestran a dos hombres queriendo formalizar su relación; entonces, obvio, se asume que los dos son gays". ${ }^{85}$

Sin embargo, no lo eran. A pesar de que ambos parecían - "a todas luces" - ser hombres de nacimiento, uno de ellos (Lukas) había llegado al mundo con vagina, asignándosele el sexo registral femenino. El otro (Elías), un hombre cisgénero, sí era gay.

Tampoco se trataba de una pareja real, sino de dos amigos que estaban realizando un experimento: querían demostrar el absurdo de hacer derivar — directamente - la identidad de género del sexo biológico. Y aunque, además, ambos poseían sexos registrales distintos (Lukas aún figuraba con sexo femenino), no se les dio hora para casarse de inmediato, como debería haber sucedido, sino que el caso fue elevado hacia los superiores jerárquicos.

Eran legalmente un hombre y una mujer, sí, pero ambos tenían una clara apariencia masculina. Nadie podría haberse imaginado que Lukas era, en realidad, "una chica que decidió borrar sus aspectos femeninos para ser lo que es: un hombre heterosexual, aunque no tiene pene". ${ }^{86}$

Un tiempo después, "de arriba" vino la orden de que, efectivamente, podían ellos casarse, bajo el argumento de que nuestra legislación sólo prohíbe el matrimonio entre personas del mismo sexo registral, pero no de un género análogo, como era el caso de Lukas y Elías.

El experimento anterior lleva naturalmente a plantearse la pregunta acerca de qué es mejor (o peor) desde la perspectiva conservadora, que defiende con fuerza una visión esencialista de la sexualidad humana: ¿que se casen dos personas de una misma apariencia (de similar expresión de género, como el caso de Lukas y Elías) o que, en cambio, lo hagan dos personas de distinta apariencia, habiendo una de ellas modificado su sexo registral?

A la luz del debate referido en este artículo, ambas alternativas serían moralmente inaceptables para el mundo conservador, aunque en mayor medida la segunda, dado que supondría reconocer legalmente una identidad sexual que desafía de un modo radical el binarismo de género. Las identidades trans, en efecto, implicarían una desviación extrema de la

${ }^{85}$ Melissa Gutiérrez, "La historia de Elías y Lukas: 'La gente no puede entender que exista un hombre sin pene"”, The Clinic (18 de febrero de 2013).

${ }^{86}$ Ibídem. 
"naturaleza" o, dicho de manera más elegante, darían cuenta de una disociación entre sexo y género.

Y precisamente, de acuerdo a lo visto, es que se ha argumentado que la ley de identidad de género produciría daños contra terceros, afectándose así los derechos de quienes se relacionan con las personas trans, que puedan eventualmente hacer uso de dicha normativa. ¿Qué sucede si un padre se cambia de sexo? ¿Se convertiría en madre? ¿Cómo es posible que un niño tenga dos madres (o dos padres, en el caso contrario)? Estas preguntas han sido frecuentes en algunos de los más encarnizados opositores a la iniciativa legal referida en este trabajo. ${ }^{87}$

Pero lo cierto es que las situaciones precedentes pueden perfectamente ya darse, y de hecho se dan hace mucho tiempo en Chile, sin la necesidad de que haya sido promulgada una ley de identidad de género y sin que, de acuerdo al procedimiento de cambio de nombre - al que históricamente han acudido las personas trans-, alguien haya logrado modificar su partida de nacimiento, en lo que al nombre y sexo registral se refiere. ${ }^{88}$

De acuerdo a lo dicho, se torna patente la conclusión de que los sectores conservadores se oponen fundamentalmente a la libertad sexual de las personas. En este sentido, la idea de supuestos daños contra terceros - que produciría el ejercicio del derecho a la identidad de género- no sería, en verdad, más que una artimaña, una suerte de trampa argumentativa, con el objetivo de rechazar — aunque de manera obli-

${ }^{87}$ Desde el punto de vista del derecho de familia, se trata de situaciones que, ya antes del proyecto, se encontraban reguladas, sea por la vía de la nulidad, del divorcio o del derecho a no disolver el matrimonio, si los cónyuges así lo estimasen. Esta última es la tesis de Espejo y Lathrop, quienes sostienen que, si el proyecto de identidad de género (cosa que terminó así ocurriendo) impusiera la disolución del matrimonio, incluso contra la voluntad de los cónyuges, por el hecho de uno de ellos haber modificado su sexo registral, constituye una disposición paternalista que apunta a proteger a los individuos de sí mismos. Ver Espejo y Lathrop, "Identidad de género", 398.

${ }^{88}$ Concretamente, al no existir en Chile una ley de identidad de género, acostumbraban ellas a hacer un uso integrado de las leyes $n .^{\circ} 4.808$ sobre Registro Civil y n. ${ }^{\circ} 17.344$ sobre cambio de nombre. El artículo 31 de la ley n. ${ }^{\circ} 4.808$ dispone que "no podrá imponerse al nacido un nombre extravagante, ridículo, impropio de personas, equívoco respecto del sexo o contrario al buen lenguaje". Por su parte, el artículo 1 de la Ley $\mathrm{N}^{\circ} 17.344$ señala que el cambio de nombre procede, entre otras causales, por menoscabo moral del solicitante y por haber sido conocido con otros nombres por más de cinco años. 
cua- la existencia misma de las personas trans: el hecho de que ellas puedan dar cuenta de una expresión de género que desafía las expectativas que derivan de su sexo biológico de nacimiento.

Lo anterior, y en buena medida a partir de evidentes y afortunados cambios culturales - que tanto en Occidente como en Chile se han experimentado en las últimas décadas - , lleva a concluir que la batalla cultural la están ganando las personas de la diversidad sexual, incluyendo las trans, siendo estas últimas las más discriminadas y agredidas, tanto en términos físicos como simbólicos.

Sin embargo, la emergencia de la denominada Alt-right en los Estados Unidos ${ }^{89}$ y la presencia de no pocos intelectuales públicos que, a ambos lados del Atlántico, tienden a victimizarse frente a las conquistas legales o administrativas de la población LGBTI (o, incluso, de las propias mujeres, en cuanto todavía se encuentran subordinadas a los hombres) ${ }^{90}$ conducen también a pensar que no todo está dicho y escrito; que nadie ha clavado aún la bandera del triunfo en materia de libertad sexual, y que, por ello, la poderosa voz de alerta de Thomas Szasz mantiene hoy plena vigencia.

Concretamente, la existencia de un mundo conservador, aún hegemónico en la derecha chilena, hace que se torne necesario que, desde el liberalismo clásico — que mira el mercado como un valioso sistema de cooperación social—, se fundamente y defienda no sólo la libertad de iniciativa económica, lo que constituye el mínimo común histórico de dicho sector político, ${ }^{91}$ sino que también — de manera más

${ }^{89}$ Alt-right es la abreviatura del término alternative right, sector político que se ha conformado como la extrema derecha en los Estados Unidos, y que se destacó por apoyar la candidatura presidencial de Donald Trump durante el año 2016. Ver, por ejemplo, Mike Wending, "“Alt-right', el controvertido 'grupo de choque' ultraderechista que defiende a Donald Trump en internet", BBC Mundo, 22 de noviembre de 2016.

${ }^{90}$ Un caso muy conocido, en el último tiempo, es el del psicólogo canadiense Jordan Peterson, profesor de la Universidad de Toronto, quien se ha opuesto tajantemente al reconocimiento legal de la identidad de género de las personas trans e, incluso, a la igualdad formal entre hombres y mujeres. Ver Cayetana Álvarez de Toledo, "Peterson: 'Hay una crisis de la masculinidad porque se culpa a los hombres por el mero hecho de serlo", El Mundo, 13 de febrero de 2018.

${ }^{91}$ Ver, a este respecto, Valentina Verbal, La derecha perdida. Por qué la derecha en Chile carece de relato y dónde podría encontrarlo (Santiago: Ediciones LYD, 2017). 
amplia - el derecho de todos a buscar su propio destino. Incluso para quienes viven una identidad de género que pone en tela de juicio el paradigma del sexo binario. En este sentido, los principios del liberalismo clásico como los que durante el siglo XX defendió Friedrich Hayek - en la estela de otros autores - no parecen haber pasado de moda. Aunque el austriaco lo hizo en otro contexto histórico - el de un estatismo creciente y de la Guerra Fría entre dos potencias mundiales-, puede decirse que todavía hoy, en el comienzo de una nueva centuria, las personas siguen teniendo el derecho a perseguir sus propios fines como si fueran fines supremos, y bajo un orden social en el que nadie, ni siquiera el poder del Estado, posea la facultad para afectarlos o restringirlos.

\section{BIBLIOGRAFÍA}

Álvarez de Toledo, Cayetana. "Peterson: 'Hay una crisis de la masculinidad porque se culpa a los hombres por el mero hecho de serlo"'. El Mundo, 13 de febrero de 2018 .

Asociación Americana de Psiquiatría (APA). DSM-5. Manual de diagnóstico $y$ estadístico de los trastornos mentales. Madrid: Editorial Médica Panamericana, 2014.

Asociación Americana de Psiquiatría (APA). DSM-IV-TR. Manual de diagnóstico y estadístico de los trastornos mentales. Barcelona: Masson, 2005.

Atria, Fernando, Guillermo Larraín, José Miguel Benavente, Javier Couso \& Alfredo Joignant. El otro modelo. Del orden neoliberal al régimen de lo público. Santiago: Debate, 2013.

Cabral, Mauro \& Gabriel Benzur. "Cuando digo intersex. Un diálogo introducción a la intersexualidad". Cademus Pagu 24 (2005): 283-304.

Capponi M., Ricardo. Psicopatología y semiología psiquiátrica [1987]. Santiago: Editorial Universitaria, 2016.

Comisión Interamericana de Derechos Humanos (CIDH). Estudio sobre orientación sexual, identidad de género y expresión de género: Algunos términos y estándares relevantes (2012).

Cooper, David. Psiquiatría y antipsiquiatría. Barcelona: Paidós, 1985.

Corral Talciani, Hernán. "Matrimonio, parejas del mismo sexo y derecho de familia”. En Matrimonio en conflicto. Visiones rivales sobre el matrimonio entre personas del mismo sexo, editado por Mauro Basaure \& Manfred Svensson, 187-208. Santiago: Editorial Cuarto Propio, 2015.

De Toro, Ximena. "Niños y niñas transgéneros: ¿nacidos en el cuerpo equivocado o en una sociedad equivocada?" Punto Género 5 (2015): 109-128. 
Del Pino, Sebastián \& Valentina Verbal. "El proyecto de ley de identidad de género. Una aproximación a sus disposiciones y fundamentos". Liminales. Escritos sobre Psicología y Sociedad 7, n. ${ }^{\circ} 1$ (2015): 180-203.

Escalante Gonzalbo, Fernando. Historia mínima del neoliberalismo. Una historia económica, cultural e intelectual de nuestro mundo, de 1975 hasta hoy. Madrid: El Colegio de México - Turner, 2016.

Espejo Yaksic, Nicolás \& Fabiola Lathrop Gómez. "Identidad de género, relaciones familiares y derechos de niños, niñas y adolescentes. Comentarios al proyecto de ley que reconoce y da proyección al derecho a la identidad de género". Revista de Derecho 22, n. 2 (2015): 393-418.

Fernández Rodríguez, María \& Elena García-Vega. "Surgimiento, evolución y dificultades del diagnóstico de transexualismo". Revista de la Asociación Española de Neuropsiquiatría 32 (2012): 103-119.

Foucault, Michel. Historia de la locura en la época clásica [1964]. México D.F.: Fondo de Cultura Económica, 2010.

Freeman, Samuel. Rawls. México D.F.: Fondo de Cultura Económica, 2016.

Gómez de la Torre, Maricruz. El sistema filiativo chileno. Santiago: Editorial Jurídica de Chile, 2007.

Gutiérrez, Melissa. "La historia de Elías y Lukas: 'La gente no puede entender que exista un hombre sin pene"”. The Clinic, 18 de febrero de 2013.

Hayek, Friedrich A. Camino de servidumbre [1944]. Madrid: Alianza Editorial, 2007.

—. Derecho, legislación y libertad [1973]. Madrid: Unión Editorial, 2014.

—. Los fundamentos de la libertad [1959]. Madrid: Unión Editorial, 2014.

_. "El individualismo: el verdadero y el falso" [1945]. Estudios Públicos 22 (1986): 2-28.

—. "Liberalismo". Revista de Ciencia Política 4, n. ${ }^{\circ} 2$ (1982): 122-151.

Hume, David. Investigación sobre el conocimiento humano [1748]. Madrid: Alianza Editorial, 1998.

Jiménez Díaz, Rafael. "La génesis de las parafilias sexuales y la homosexualidad egodistónica: el modelo de los mecanismos tensionales". Avances en Psicología Latinoamericana 30, n. ${ }^{\circ} 1$ (2012): 146-158.

Kamen, Henry. Nacimiento y desarrollo de la intolerancia en la Europa moderna [1967]. Madrid: Alianza Editorial, 1987.

Mas Grau, Jordi. Subjetividades y cuerpos gestionados. Un estudio sobre la patologización y medicalización del transgénero. Tesis para optar al grado de doctor en antropología por la Universidad de Barcelona (2014).

Matteucci, Nicola. "Liberalismo". Diccionario de política [1976], dirigido por Norberto Bobbio, Nicola Matteucci \& Gianfranco Pasquino. Madrid: Alianza Editorial, 1991: 875-897.

Missé, Miguel \& Gerald Coll-Planas. "La patologización de la transexualidad. Reflexiones críticas y propuestas". Norte de Salud Mental VIII, n. ${ }^{\circ} 38$ (2010): 44-55. 
Mizhari, Mauricio Luis. Homosexualidad y transexualismo. Buenos Aires: Astrea, 2016.

Nozick, Robert. Philosophical Explanations. Cambridge: Harvard University Press, 1981.

- Puzzles socráticos. Madrid: Ediciones Cátedra, 1999.

Organización Mundial de la Salud (OMS). CIE-10. Manual de trastornos mentales $y$ del comportamiento. Descripciones clínicas y pautas para el diagnóstico. Madrid: Meditor, 1992.

Organización Panamericana de la Salud (OPS). Por la salud de las personas trans. Elementos para el desarrollo de la salud integral de personas trans y sus comunidades en Latinoamérica y el Caribe (2013).

Page, Olof. "Las formas y usos de la vulnerabilidad". En Los invisibles. Por qué la pobreza y la exclusión dejaron de ser propiedad, editado por Catalina Siles V. Santiago: Instituto de Estudios de la Sociedad, 2015.

Popper, Karl. La sociedad abierta y sus enemigos [1945]. Barcelona: Paidós, 2017.

Principios de Yogyakarta. Principios sobre la aplicación de la legislación internacional en relación con la orientación sexual y la identidad de género (2006).

Rawls, John. El liberalismo político [1993]. México D.F.: Fondo de Cultura Económica, 2006.

Riego, Cristián \& Álvaro Paul. "Frente a frente: ¿Es correcto el fallo de la CS que permite el cambio de nombre y sexo registral?". La Tercera, 9 de junio de 2018.

Robles, Víctor Hugo. Bandera hueca. Historia del movimiento homosexual en Chile. Santiago: Arcis - Cuarto Propio, s/f.

Rothbard, Murray N. La ética de la libertad [1982]. Madrid: Unión Editorial, 2009.

Schwember, Felipe. "Igualdad o igualitarismo. Dos perspectivas acerca de la justicia”. Estudios Públicos 147 (2017).

Siles, Catalina \& Gustavo Delgado. "Teoría de género: ¿de qué estamos hablando? 5 claves para el debate". Documento de trabajo, Instituto de Estudios de la Sociedad (IES) y Comunidad y Justicia (CJ). Santiago: IES, 2014.

Szasz, Thomas S. La fabricación de la locura [1970]. Barcelona: Editorial Kairós, 2006.

Verbal, Valentina. La derecha perdida. Por qué la derecha en Chile carece de relato y dónde podría encontrarlo. Santiago: Ediciones LYD, 2017.

—. "Personas trans en Chile. ¿Por qué es necesaria una ley de identidad de género?” En Material(es) de formación general I DD.HH., de varios autores, 27-35. Santiago: Universidad Viña del Mar, 2014.

Villavicencio Miranda, Luis. Las críticas comunitaristas al liberalismo igualitario. Un balance. Alcalá de Henares: Universidad de Alcalá, 2014.

Weber, Max. El político y el científico. Madrid: Alianza Editorial, 1979.

Wending, Mike. “'Alt-right', el controvertido 'grupo de choque' ultraderechista que defiende a Donald Trump en internet”. BBC Mundo, 22 de noviembre de 2016.

World Professional Association Transgender Health (WPATH). Normas de atención para la salud de personas trans y con variabilidad de género (2012). EP 